\title{
Rapid Enzymatic Hydrolysis of Crambe Oil Catalyzed by Castor Seeds Lipases
}

\author{
Fernanda Tavares ${ }^{1}$, Pamella Sackser ${ }^{1}$, Carlos Borba $^{1}$, and Edson Silva ${ }^{1}$ \\ ${ }^{1}$ Universidade Estadual do Oeste do Parana - Campus de Toledo
}

June 10, 2020

\begin{abstract}
A rapid and eco-friendly method, using ultrasound power, was successfully employed to hydrolyze Crambe oil using lipase enzymes directly from castor seeds, in oil-free and in natura forms. A yield of $86 \%$ conversion of triglycerides into free fatty acids (FFA) was achieved in 5 minutes using in natura seeds and $73 \%$ of conversion when performing the reaction with oil-free seeds. The operational conditions of ultrasound power, mass ratio of buffer solution and oil, catalyst, and total substrate were evaluated using a central composite rotatable design (CCRD). The hydrolysis yield was optimized by Response Surface Methodology. The optimum conditions were approximately $70 \%$ of ultrasound power (350 W), 1.79 buffer solution/oil mass ratio, and 0.25 catalyst/substrate mass ratio for in natura seeds. For the oil-free seeds, the optimal conditions found were $68 \%(340 \mathrm{~W})$ of ultrasound power, 1.67 buffer solution/oil mass ratio, and 0.06 catalyst/substrate mass ratio. Mathematical modeling was applied to the experimental kinetic data, and it was possible to predict FFA concentration values from independent experiments.
\end{abstract}

\section{Rapid Enzymatic Hydrolysis of Crambe Oil Catalyzed by Castor Seeds Lipases}

F. Tavares ${ }^{\text {a+* }}$, P. R. Sackser ${ }^{\text {a }}$, C. E. Borba ${ }^{\text {a }}$, E. A. Silva ${ }^{a}$

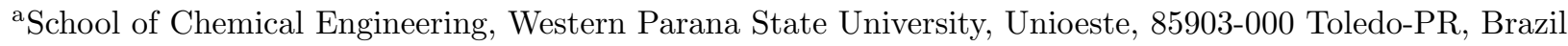

${ }^{*}$ Corresponding author: email address: fernandatavareseq@hotmail.com, phone number: M: +966 562261696

Abstract: A rapid and eco-friendly method, using ultrasound power, was successfully employed to hydrolyze Crambe oil using lipase enzymes directly from castor seeds, in oil-free and in natura forms. A yield of $86 \%$ conversion of triglycerides into free fatty acids (FFA) was achieved in 5 minutes using in natura seeds and $73 \%$ of conversion when performing the reaction with oil-free seeds. The operational conditions of ultrasound power, mass ratio of buffer solution and oil, catalyst, and total substrate were evaluated using a central composite rotatable design (CCRD). The hydrolysis yield was optimized by Response Surface Methodology. The optimum conditions were approximately $70 \%$ of ultrasound power $(350 \mathrm{~W}), 1.79$ buffer solution/oil mass ratio, and 0.25 catalyst/substrate mass ratio for in natura seeds. For the oil-free seeds, the optimal conditions found were $68 \%(340 \mathrm{~W})$ of ultrasound power, 1.67 buffer solution/oil mass ratio, and 0.06 catalyst/substrate mass ratio. Mathematical modeling was applied to the experimental kinetic data, and it was possible to predict FFA concentration values from independent experiments.

Keywords : vegetal enzymes; ultrasound; residue enzymes

\section{Introduction}

The hydrolysis of oils and fats to produce free fatty acids has noteworthy industrial importance as it is required in the pharmaceutical, energy, food, chemical, and cosmetic industries, including coatings, adhesives, biofuels, surfactants, shampoos, and other personal care products (Avelar et al., 2013; Noor et al., 2003). The 
usual industrial process for the hydrolysis to take place, the Colgate-Emery process, entails high temperature (at least $250^{\circ} \mathrm{C}$ ) and pressure (4.82 MPa) (Barnebey and Brown, 1948), implying in a high energy cost in addition to undesirable reactions and by-products formation (Rooney and Weatherley, 2001). Oil hydrolysis can also be performed by employing chemical catalysts (Da Silva et al., 2016; Devaraj et al., 2018; Ong et al., 2016), enzymatic catalysts (lipases) (Cavalcanti-Oliveira et al., 2010; Corradini et al., 2019; de Sousa et al., 2010; El-Hefnawy and Sakran, 2014; Goñi et al., 2018; Santos et al., 2013), using subcritical water (Almeida et al., 2017; dos Santos et al., 2019; Ilham and Saka, 2010; Xiao et al., 2017) or other less conventional methods as microwave irradiation (Nguyen et al., 2020) and the use of ionic liquids (Han et al., 2019).

The enzymatic method presents the advantage of being performed under mild conditions of pressure and temperature, which allows the reduction of costs associates with energy and equipment; nonetheless, waste treatments are also reduced (Posorske, 1984). A common drawback from the use of enzymes, however, is the high price of isolation and purification of microbial and animal enzymes, which restrict their industrial application on a large scale (Du et al., 2008). In this sense, the use of vegetable lipases can be an attractive alternative considering that it can be obtained from renewable sources, produced on a large scale, and does not require a high level of purification (Campillo-Alvarado and Tovar-Miranda, 2013; Villeneuve, 2003).

During the germination of oilseeds, hydrolysis of acylglycerols takes place, and lipases are activated to catalyze the process (Abigor et al., 2002; Hills and Murphy, 1988; Muto and Beevers, 1974). Nevertheless, it has been reported that in castor bean seeds, lipases were activated not only during germination, as most of the known seeds, but also in dormant seeds (Eastmond, 2004; Fuchs et al., 1996; Muto and Beevers, 1974). The castor seed oil is widely used for pharmaceutical and cosmetic industries, the castor seed cake, however, is poisonous to humans and animals, since the toxic protein ricin is present (Martínez et al., 2018; Meneguelli de Souza et al., 2018). The use of castor seeds, only in the oil-free form, as lipase source has been reported in the literature before [1,10,11,13,31-34], and reaction times range between 2 to 10 hours. It is not from the author's knowledge of any study involving ultrasound to the enzymatic hydrolysis reaction using vegetal seeds as a catalyst.

In the oil hydrolysis reaction catalyzed by lipases, the reaction takes place on the aqueous-organic interface (Al-Zuhair et al., 2003; Ferreira-Dias and da Fonseca, 1995); however, the viscosity and immiscibility of the substrates are high, and the phenomenon of mass transfer controls the reaction rate (Romero et al., 2007; Talukder et al., 2006). Therefore, increasing the interface by generating an emulsion can improve the rate (Feiten et al., 2014; Lerin et al., 2014; Talukder et al., 2006) and facilitate the use of biocatalysts on the industrial scale (De Freitas et al., 2019). Ultrasound creates emulsion by generating the phenomenon of cavitation, which consists of the growth and collapse of bubbles and, consequently, the generation of shockwaves (Ho et al., 2016). Reduced and dispersed liquid droplets can be formed through this system (Leong et al., 2009; Talukder et al., 2006). Compared to typical mixing methods, enzymatic reactions under ultrasonic treatment achieve higher equilibrium values as well as higher selectivity and reduction (Chiplunkar et al., 2018; Lerin et al., 2014; Polachini et al., 2019). However, due to thermal and mechanical (high shear stress and pressure, causing dissociation of enzyme) effects (Froment et al., 1998; Vercet et al., 2001), some studies reported a loss of enzymatic activity during the process $[48,49]$. Therefore, its impact on the activity of enzymes is intricate (Barton et al., 1996). The information on the kinetics, along with the assessment of the variables process conditions, can provide practical information about the performance of ultrasound-assisted hydrolysis of oil with vegetal lipase to contribute to the scale-up of the process (Polachini et al., 2019).

The non-edible oilseed Crambe Abyssinian (Brassicaceae family) is a low-cost raw material with high oil content and a high percentage of monounsaturated fatty acids (mostly erucic acid, C22:1, 50-60\% on average) which grants high stability to the oil (Lazzeri et al., 1994; Wazilewski et al., 2013), representing an attractive option of sustainable raw material. Furthermore, the advantages of using a low-cost raw material, castor bean seeds, as a lipase source for hydrolysis reactions are clear. However, studies are still necessary for the process to become industrial. Understanding of the reaction mechanism and optimization of reaction conditions are essential tools for scaling-up. In this work, we studied the optimation of conditions for the enzymatic hydrolysis reaction performed under ultrasound treatment, using in natura and oil-free castor seeds. Under 
this treatment, the reaction rate is fast as well as the lipase deactivation; therefore, the modeling of the kinetic experiments can be relevant for optimized use of this enzymatic catalyst under harsh conditions as it is the use of ultrasound power.

\section{Material and Methods}

\subsection{Reagents}

The commercial castor bean seeds were bought from the Brazilian company BRSeeds, and the Crambe oil was donated by the research company MS Foundation, located in Maracaju - MS, Brazil. Ethyl ether, ethanol, hexane, acetone, sodium hydroxide, and phenolphthalein were used with minimum purities of $99 \%$.

\subsection{Preparation of Castor Seed Particles}

\subsubsection{In Natura Seeds}

In natura castor seeds were ground with a blender, and the seed particles smaller than $4.8 \mathrm{~mm}$ were collected after sieving.

\subsubsection{Oil-Free Seeds}

To prepare the oil-free seeds, a methodology reported elsewhere was used with slight modifications (Cavalcanti et al., 2007). Approximately $10 \mathrm{~g}$ of castor bean seeds were peeled and ground, then $50 \mathrm{~cm}^{3}$ of acetone was added to the particles and were left under constant stirring at $4^{\circ} \mathrm{C}$ for $16 \mathrm{~h}$. Subsequently, the seeds were filtered under vacuum and left to dry at room temperature for $24 \mathrm{~h}$. Particles of less than $1 \mathrm{~mm}$ were collected after sieving. The average of oil extracted following this methodology was $47.4 \pm 1.3 \%$.

\subsection{Quantification of FFA}

Titration with $\mathrm{NaOH}$ solution was performed to quantify the FFA (free fatty acids) following the AOCS official method (Ca 5a-40) (AOCS, 1996).Equation 1 was employed to calculate the mass percentage of FFA in the samples.

Where $\mathrm{m}$ is the sample oil mass $(\mathrm{g}), V$ is the volume of $\mathrm{NaOH}$ solution used in the titration $(\mathrm{L}), M_{\mathrm{NaOH}}$ is the $\mathrm{NaOH}$ solution molarity $\left(\mathrm{mol} \mathrm{L} \mathrm{L}^{-1}\right)$ andMM $\mathrm{FFA}_{\mathrm{FA}}$ is the average molar mass of fatty acids in Crambe oil. The average molar mass of fatty acids in Crambe oil is $317.98 \mathrm{~g} \mathrm{~mol}^{-1}$, and it was determined in previous work (Tavares et al., 2018b) performed by the same group.

\subsection{Quantification of Acylglycerols}

Analysis of Nuclear Magnetic Resonance (NMR) was performed to determine the concentration of acylglycerols and the methodology is described elsewhere (Tavares et al., 2018a).

\subsection{Hydrolysis Reactions}

The reactions were carried out in a $50 \mathrm{~mL}$ Erlenmeyer sonicated using an Ultronique ultrasound, microtip probe of $4 \mathrm{~mm}$ diameter, model disruptor, maximum power of $500 \mathrm{~W}$. Additional experiments were performed in a refrigerated incubator with agitation (shaker) at room temperature and $140 \mathrm{rpm}$. 
During preliminary tests, it was observed that after 5 minutes of sonication, the viscosity of the medium started to increase, affecting the cavitation phenomenon. The temperature of the mixture was increasing (more than $40^{\circ} \mathrm{C}$ ), which could be damaging for the reaction and the equipment. Therefore, for the factorial design experiments, a time of 3 minutes was chosen. A fixed volume of $25 \mathrm{~cm}^{3}$ of water and oil solution (acetate buffer solution; $0.2 \mathrm{M}, \mathrm{pH} 4.2$ ) was used. The buffer solution $\mathrm{pH}$ and concentration were determined based on preliminaries studies performed by the same research group (TAVARES et al., 2015).

After the reaction time, the resulting hydrolyzed oil emulsion was centrifuged for 20 minutes at $3000 \mathrm{rpm}$, and then a sample of approximately $1 \mathrm{~g}$ of oil was collected and analyzed. The hydrolysis yield was calculated by Equation 2 .

$$
\overline{\text { Yield }=\frac{\text { FFA (\%)-FFA(\%) }}{\text { Initial }} \quad(\mathbf{2})}
$$

In which, $F F A(\%)_{\text {Initial }}$ is the initial acidity of the Crambe oil.

\subsubsection{CCRD Experiments}

The effects of the mass ratio of buffer solution/oil (B/O), catalyst/substrate $(\mathrm{C} / \mathrm{S})$, and ultrasound power (Po) were assessed through the use of a Central Composite Rotational Design (CCRD) with central and axial points, the values of the design were determined after preliminary experiments. Seventeen essays were performed for each design, with three replicates on the central point, and six experiments of axial points. The variable levels of the CCRD for in natura seeds were: ultrasound power of $31.40 \%, 45.0 \%, 65.0 \%, 85.0 \%$; and $98.64 \%$; $\mathrm{B} / \mathrm{O}$ mass ratio $0.07,0.45,1.00,1.55$, and 1.93 ; and $\mathrm{C} / \mathrm{S}$ mass ratio of $0.01,0.07,0.16,0.25$, and 0.31 . For the oil-free seed particles: $31.40 \%, 45.0 \%, 65.0 \%, 85.0 \%$, and $98.64 \%$ for ultrasound power; $1.13,1.40,1.80,2.20$, and 2.47 for the $\mathrm{B} / \mathrm{O}$ mass ratio; and $0.010,0.020,0.035,0.050$, and 0.060 for $\mathrm{C} / \mathrm{S}$ mass ratio. All the experiments were carried out for three minutes. The response of the experimental design was the hydrolysis yield, analyzed through the software Statistica version 7.0 (StatSoft Inc., USA). The validation of the model was performed with the software Maple version 13.0 (Waterloo Maple Inc., Canada).

\subsubsection{Kinetic Experiments}

Kinetic experiments were performed at the conditions of higher yield obtained during the CCRD experiments, where for each reaction time, a different test was performed. Additional experiments were performed in a refrigerated incubator with agitation (shaker) at room temperature and $140 \mathrm{rpm}$.

\subsection{Mathematical Modeling}

A simplified kinetic mechanism for enzyme-catalyzed hydrolysis reactions was employed in this work; the mechanism equations and molar balances are described in a previous work performed by the same research group (Tavares et al., 2018b). The assumptions for the closed and batch system were considered the same for the ultrasound system as for the conventional stirring batch process: Enzymatic hydrolysis reaction defined using the simplified Ping Pong Bi Bi (PPBB) mechanism; Elementary reaction rate; Ideal mixture in the liquid phase; and Isobaric and isothermal process.

To solve the equation system the following initial conditions were used: $C_{\mathrm{TAG}}(0)=0.27 \frac{\mathrm{mol}}{\mathrm{Kg}}, C_{\mathrm{DAG}}(0)=$ $0 \frac{\mathrm{mol}}{\mathrm{Kg}}, C_{\mathrm{MAG}}(0)=0 \frac{\mathrm{mol}}{\mathrm{Kg}}, C_{H_{2} O}(0)=29.14 \frac{\mathrm{mol}}{\mathrm{Kg}}, C_{\mathrm{GL}}(0)=0 \frac{\mathrm{mol}}{\mathrm{Kg}}, C_{\mathrm{FFA}}(0)=0.08 \frac{\mathrm{mol}}{\mathrm{Kg}}$, and $C_{E}(0)=$ $C_{E}^{\text {total }}=3.5 \times 10^{-4} \frac{\mathrm{mol}}{\mathrm{Kg}}$ for in natura seeds; and $C_{\mathrm{TAG}}(0)=0.34 \frac{\mathrm{mol}}{\mathrm{Kg}}, C_{\mathrm{DAG}}(0)=0 \frac{\mathrm{mol}}{\mathrm{Kg}}, C_{\mathrm{MAG}}(0)=$ $0 \frac{\mathrm{mol}}{\mathrm{Kg}}, C_{H_{2} O}(0)=33.72 \frac{\mathrm{mol}}{\mathrm{Kg}}, C_{\mathrm{GL}}(0)=0 \frac{\mathrm{mol}}{\mathrm{Kg}}, C_{\mathrm{FFA}}(0)=0.10 \frac{\mathrm{mol}}{\mathrm{Kg}}$, and $C_{E}(0)=C_{E}{ }^{\text {total }}=$ $1.6 \times 10^{-4} \frac{\mathrm{mol}}{\mathrm{Kg}}$ for oil-free seeds. The considered molecular mass of the enzyme was $59 \mathrm{kDa}$ (Eastmond, 2004 ) and the enzymatic concentrations were calculated considering $17 \%$ of proteins (lipases) on the castor bean seeds bodies (Tully and Beevers, 1976). 
Rosenbrock's numerical method (Rosenbrock, 1963) coded in Maple@ software was used to solve the mathematical model with the initial conditions.

The enzymatic hydrolysis kinetics experimental data was used to estimate the parameter values in the mathematical model $\left(k_{1}, \ldots, k_{12}\right)$ employing the minimization of the objective function (Equation 3) through the Simplex Dowhill optimization method (Nelder and Mead, 1964).

$$
\text { O.F. }=\sum_{j=1}^{\mathrm{nc}} \sum_{i=1}^{\mathrm{nd}}\left(C_{j, i}^{\mathrm{exp}}-C_{j, i}^{\mathrm{mod}}\right)^{2}
$$

Where refers to the component (i.e., TAG, DAG, MAG, FFA), is the experimental data number, is the experimental concentration, and is the model calculated concentration of component $j$.

\section{Results and Discussion}

It was verified, during preliminary tests, that due to the oil present in the in natura seeds, the particles of this type of seeds were aggregating. Thus, the in natura seeds were used in a bigger granulometry compared to the oil-free seeds.

\subsection{CCRD Results for In Natura Seeds}

In Table 1 the results of assays for the use of in natura seeds as catalysts are presented, with a observed variation of 3.97 to $84.51 \%$ in the yield of the enzymatic hydrolysis. In the Pareto graph (Figure 1 ) the significant variables (95\% of significance level) were identified being the catalytic/substrate and buffer/oil mass ratios, with positive linear effects and negative quadratic effects on the yield. The catalyst/substrate ratio is the most significant effect, and the ultrasound power variable was not significant in the evaluated conditions.

The RSM equation is given by Equation (10). The f-test was employed to evaluate the model. The calculated f-value (67.19) was notably higher than the critical f-value (3.68), from the analysis of variance (ANOVA), which validates the model statistically within the studied range. The regression model accuracy can also be observed based on the coefficient of determination $\left(\mathrm{R}^{2}\right)$ of 0.99 , indicating that the enzymatic hydrolysis yield of the Crambe oil can be well described as a function of ultrasound power and catalytic/substrate and buffer/oil mass ratios (Equation 4 ) in the investigated conditions range.

**Table 1 here**

**Figure 1 here**

Yield $(\%)=58.95-1.19 * P o-0.04 * P o^{2}+16.12 * \frac{B}{O}-6.05 *\left(\frac{B}{O}\right)^{2}+20.70 * \frac{C}{S}-5.93 *\left(\frac{C}{S}\right)^{2}+0.58 * P o * \frac{B}{O}+1.56 * P o$

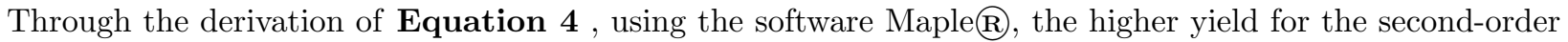
equation was found under conditions of $70 \%$ ultrasound power, 1.79 mass ratio buffer solution/oil, and 0.25 mass ratio of catalyst/substrate, in the fixed condition of 3 minutes at initial room temperature, with a yield of $87.98 \%$. In the same conditions, one experiment was carried out yielding $85.0 \pm 2.6 \%$, which confirms that within the studied range, the model can predict the yield satisfactorily.

The response surface plot for the enzymatic hydrolysis yield of the Crambe oil with in natura seeds is presented in Figure 2. Each of the variables can affect the hydrolysis reaction by giving more or less energy to the system, causing enzymatic denaturation, modifying the medium viscosity, and altering the availability of sites for lipase catalysis. The ultrasound power, however, does not have a significant effect on the response surfaces in the investigated range, unlike the $\mathrm{B} / \mathrm{O}$ and $\mathrm{C} / \mathrm{S}$ variables. Although the amount of buffer solution affects the yield of the enzymatic hydrolysis reaction, this effect will have less influence on the reaction yield 
above 1.0 (Figure 2-a ). A similar effect is observed in Figure 2-b, where for a ratio of catalyst/substrate above 0.15 , the impact of the variable is less significant; conversely, an increase in the yield can still be observed when increasing the ultrasound power. Notably, a high amount of catalyst (in natura seeds) makes the reaction medium more viscous, demanding more ultrasound power to emulsify the medium, resulting in the correlation of the two variables. In Figure 2-c , the effect of the most significant variables is evaluated simultaneously, and a higher correlation between both variables can be observed, resulting in increased yield as both variables increase.

**Figure 2 here**

\subsection{Kinetics of Ultrasound-assisted Enzymatic Hydrolysis for In Natura Seeds}

The reactions were performed under the conditions of the optimal values obtained from Equation 4 (Power $70 \%$ for 3 minutes at initial room temperature, $1.8 \mathrm{~B} / \mathrm{O}$, and $0.25 \mathrm{C} / \mathrm{S}$ ) at $\mathrm{pH} 4.2$. The experimental data is shown in Figure 3. As can be seen after 5 minutes the reaction reaches equilibrium at approximately $88 \%$ of FFA $\left(0.75 \mathrm{~mol} \mathrm{~kg}^{-1}\right)$. Besides, it has been verified that the ultrasound equipment heats up beyond usual when a time greater than 7 minutes is used, and, therefore, it is not possible to continue the reaction with the ultrasound. To evaluate the degree of enzyme deactivation and the potential of a higher yield of hydrolysis under the optimal conditions, experiments were carried out by continuing the reaction after 5 minutes in ultrasound in a refrigerated incubator with agitation (shaker) at room temperature and $140 \mathrm{rpm}$. After 30 minutes in the shaker, a yield of $89.96 \%$ was achieved for the hydrolysis reaction, and after 60 minutes, the yield was $91.57 \%$. The absence of a significant increase in the hydrolysis yield, expose the deactivation of the catalyst after the 5 minutes under ultrasonic treatment, which is consistent with a result reported by Awadallak et al. (Awadallak et al., 2016), who studied the hydrolysis of soybean oil under ultrasound treatment, using a phospholipase as catalyst. The authors reported enzyme inacvation after 10 minutes when using $20 \%$ of ultrasound power $(200 \mathrm{~W}$ ) and after 5 minutes when using $50 \%$ of ultrasound power.

To better analyze the influence of employing ultrasound in the reaction, the same experiment, under the optimal conditions found throughEquation 4, was conducted in the refrigerated incubator (140 rpm) for 3 minutes. The yield obtained was $41.23 \pm 2.62 \%$, which is less than half of the yield obtained under 3 minutes of reaction under ultrasound treatment, $85.01 \%$, demonstrating the high potential for the use of ultrasound in the enzymatic hydrolysis of Crambe oil using seeds in natura.

In Figure 3 , the concentration profiles of MAG, DAG, and TAG (in mol kg-1) are shown. The decrease in TAG (Figure 3 (d) ) concentration and increasing concentration of FFA (Figure 3 (a) ) are the expected behavior and can be seen. DAG (Figure 3 (c)) and MAG (Figure 3 (b) ), behave in the usual way for intermediate compounds of a reaction. All the concentration profiles obey the principle of mass conservation (constant , $i=T A G, D A G, M A G, G L, \mathrm{H}_{2} \mathrm{O}$ e FFA ). Additionally, inFigure 3, the model results for the concentration profiles of glycerol (Figure 3 (e) ) and water (Figure 3 (f) ) are shown. The value of $88 \%$ ([?] $0.75 \mathrm{~mol} \mathrm{~kg}^{-1}$ ) was reached after the equilibrium of the enzymatic hydrolysis of the Crambe oil in 5 min.

In Table 2 are presented the values of the estimated parameters from the fitting of the model, based on the Ping Pong Bi Bi (PPBB) kinetic mechanism, to the experimental kinetic data. The simulated and experimental curves are shown in Figure 3 . The coefficient of determination (R2) values were 1.00, 0.95, 0.88 , and 0.99 for TAG, DAG, MAG, and FFA experimental data, respectively, which demonstrate that the kinetic model satisfactorily represented the set of experimental data.

\section{**Figure 3 here**}

**Table 2 here**

With rate constants ( $k_{i}$-values) available, the mathematical model can be used to predict the reaction yield values under the same temperature condition. CCRD experiments performed under similar ultrasound power as which the kinetics were obtained were selected so the model could be applied with different initial conditions. The ultrasound power affects the temperature of the system and, thus, the equilibrium. Hence, 
the values of the FFA yield obtained experimentally and predicted by the model are shown in Table $\mathbf{3}$. The model was able to predict FFA yield under the conditions evaluated with an average deviation of $17.32 \%$. Since the data used for this validation was not obtained in the exact conditions of ultrasound power, a variation was expected. The applied model was, therefore, satisfactory to explain the reaction mechanisms and can be useful for phenomenological studies and process optimization.

\section{**Table 3 here**}

\subsection{CCRD Results for Oil-Free Seeds}

In Table 4 are presented the experimental data using oil-free seeds as the enzymatic catalyst, where an enzymatic hydrolysis yield variation of 28.27 to $69.30 \%$ in the investigated conditions can be observed.

Through the Pareto graph (Figure 4 ) it is found that all variables were significant (95\% level of significance), including the interactions between the variables, with the highest effect variable being the catalyst/substrate ratio, followed by the linear effect of the buffer/oil ratio and the interaction between the two variables. The RSM equation is given by Equation (5). The f-test was employed to evaluate the model, and the calculated f-value (18.06) was again higher than the critical f-value (3.68). Hence, the regression model is statistically valid, and satisfactorily represent the experimental data within the studied conditions range. The coefficient of determination $\left(\mathrm{R}^{2}\right)$ of 0.96 establish the accuracy of the regression model with the experimental data.

**Table 4 here**

**Figure 4 here**

Yield $(\%)=61.66+0.63 * P o-0.61 * P o^{2}+3.17 * \frac{B}{O}-0.55 *(B / O)^{2}+10.68 * \frac{C}{S}-3.75 *\left(\frac{C}{S}\right)^{2}+0.55 * P o * \frac{B}{O}-0.20 *$

Through the use of the software Maple $\AA$, the derivative of the above equation was found with the conditions of $67.8 \%$ ultrasound power, 1.67 mass ratio buffer solution/oil, and 0.06 mass ratio of catalyst/substrate, yielding $69.50 \%$. The experimental yield result found under the above conditions was $71.50 \pm 2.5 \%$, confirming that within the investigated conditions, the model can satisfactorily describe the yield of the hydrolysis reaction.

In Figure $\mathbf{5}$ are presented the response surface plots for enzymatic hydrolysis yield of the Crambe oil with oil-free seeds as a catalyst. In Figure 5-a , it is observed that the highest yield region is in the highest ultrasound power and buffer solution/oil mass ratio region. When the power effect is evaluated together with the amount of catalyst (Figure 5-b ), the result is different from the seeds in natura. When a higher power was needed for higher values of catalyst ratio, the two variables had little correlation, and a parabolic effect was observed for the catalyst/substrate ratio effect, with the yield reaching a maximum value at a ratio of approximately 0.05 . After that, a small drop occurred, indicating that in this range, the substrate is already saturated with the enzyme, and the increase only hinders the reaction by increasing the viscosity of the medium. InFigure 5-c, an interesting effect is observed. The higher the amount of buffer solution added to the reaction, the lower the amount of catalyst required for a good yield. The opposite was also observed, the higher the amount of catalyst, the less amount of solution was necessary. With these results, it is possible to perform a cost analysis to determine the best conditions under particular situations.

\section{**Figure 5 here**}

\subsection{Kinects of Ultrasound-assisted Enzymatic Hydrolysis with Oil-Free Seeds}

In the optimal experimental conditions obtained through Equation (4) (68\% power, $1.7 \mathrm{~B} / \mathrm{O}$, and 0.06 $\mathrm{C} / \mathrm{S}$ ), a kinetic experiment was performed, and the result is shown in Figure 6 . As observed, after 5 minutes, the reaction reaches equilibrium with approximately $75 \%$ FFA $\left(0.79 \mathrm{~mol} \mathrm{~kg}^{-1}\right)$.

Since there was no further advance of the hydrolysis reaction after 5 minutes and to evaluate the deactivation 
of the enzymatic catalyst, one following step was carried out for extra 30 minutes in a refrigerated incubator (140 rpm). A yield of $76.6 \pm 2.62 \%$ was achieved, indicating the catalyst deactivation, and therefore, the hydrolysis reaction could not proceed.

To evaluate the effectiveness of the ultrasound, an experiment was conducted under the optimal conditions found with Equation 5 in a refrigerated incubator (140 rpm) for 3 minutes and the yield obtained was 8.97 $\pm 2.62 \%$, considering that the yield after 3 minutes of reaction under ultrasound effect was $71.47 \pm 2.62 \%$, it is clear that the use of ultrasound represents an excellent improvement for the hydrolysis reaction.

MAG, DAG, and TAG (in mol kg-1) concentration profiles are displayed in Figure 6. The expected behaviors for the concentration profiles of TAG (Figure 6 (d)), DAG (Figure 6 (c)), and MAG (Figure 6 (b)) can be observed for this case as in the previous case, decrease in TAG concentration and FFA concentration increase (Figure 6 (a) and parabolic behaviors for DAG and MAG concentrations. The model values for the concentration profiles of glycerol (Figure 6 (e)) and water (Figure 6 (f)) are also shown in Figure 6. The equilibrium of the enzymatic hydrolysis reaction was reached in 5 min, achieving $75 \%$ ([?] $0.79 \mathrm{~mol} \mathrm{~kg}^{-}$), a lower value when compared to in natura seeds as the catalyst. In Table $\mathbf{5}$ are presented the values for the estimated parameters from the fitting of the model with the experimental kinetic data, and the curves are displayed in Figure 6. The coefficient of determination values (R2) were 0.99, 0.97, 0.99, and 0.99 for TAG, DAG, MAG, and FFA experimental data, respectively. All results imply a satisfactory description of the experimental data by the kinetic model.

\section{**Figure 6 here**}

\section{**Table 5 here**}

Independent experimental data from the CCRD experiments performed at a similar ultrasound power (65\%), at which the kinetics were obtained $(68 \%)$, were selected to test the ability of the model in predicting the reaction yields. The experimental and predicted FFA yield values are shown in Table 6 . It can be concluded that the model was able to predict the hydrolysis yield within the evaluated range of the conditions, with an average deviation of $11.46 \%$. The model was, therefore, suitable to explain the mechanism of the reaction of enzymatic hydrolysis of vegetal oil using vegetal lipases and can useful for phenomenological studies and process optimization.

\section{**Table 6 here**}

\subsection{Comparison Between the Enzymatic Seed Particles}

To the author's knowledge, there is no work in the literature evaluating the use of ultrasound in the oil hydrolysis reaction, using castor seeds in any form as a lipase source. Previous work was conducted employing castor seeds, in natura and oil-free forms, to the enzymatic hydrolysis of Crambe oil, from the same research group (Tavares et al., 2018a) and will be used as a comparison between the seed particles with and without the ultrasonic treatment. The previous results, along with the results presented in this work, are summarized in Table 7 . It is essential to highlight that although different granulometry was used among the forms of catalyst seeds, the comparison can still be useful, as only the kinetic of the reaction will be impacted, reaching equilibrium at different times but without changing the equilibrium condition (final yield of the reaction).

\section{**Table 7 here**}

Higher levels of potency increase the emulsification of the reactants facilitating the hydrolysis reaction (Ozbek and Ulgen, 2000; Wang et al., 2015), however, the enzymatic deactivation effect may also occur due to the thermal effect generate through the ultrasonic treatment, given that the reaction temperature increases during cavitation, besides of the shear and pressure forces that cause damage to the structure of the enzyme (Froment et al., 1998; Vercet et al., 2001). The effect of temperature in the enzymes activities is well know, in one example, Avelar et al. (Avelar et al., 2013) reported on the influence of temperature in 
enzymatic hydrolysis of canola oil employing oil-free castor seeds as a lipase source; the activity decreased with temperature increase after 50degC. Cavalcanti et al.(Cavalcanti et al., 2007), shown similar deactivation of oil-free castor seeds after 40degC. The effect of deactivation by the ultrasound power was notable after 5 minutes of reaction, and small or no further activity was detected after this time when the reaction was continued in a shaker; also it can be noted that the equilibrium yield for the oil-free seeds was lower, suggesting that the enzymes may have suffered a more significant deactivation in this reaction system.

Despite the fact that the lipase concentration is higher on oil-free seeds, another aspect that allows the use of significantly less amount of the catalyst mass, is the smaller granulometry of the oil-free seeds, which provides a higher superficial area favoring the aqueous-organic interfacial reaction (Pourzolfaghar et al., 2016). Besides, a more substantial amount of buffer solution was needed for both particle forms when the reaction was performed in ultrasound since the emulsion of the system is better, and the aqueous-organic interface increased.

Comparing the yield of reaction at an equivalent time, both systems exhibit similar behavior under optimal ultrasound conditions. The oil-free seeds, however, reached equilibrium at a lower yield compared with in natura seeds, which is resulted from the less stability and higher deactivation of oil-free seeds, since in previous experiments, it was demonstrated that after 30 days at $4 \mathrm{deg} \mathrm{C}$ the oil-free seeds had $9 \%$ of deactivation while no deactivation detected for the in natura seeds (Tavares et al., 2018a). The deactivation can be accelerated by the ultrasound power used in the reaction. However, notably, the reaction could be intensified with the use of ultrasound since the time of 4 hours for a yield of $86 \%$ (Tavares et al., 2018a) was decreased to 5 minutes of reaction with the in natura seeds. Other intensification process methods can be performed with microwaves. Nguyen et al. (Nguyen et al., 2020) reported a green approach to produce FFA from soybean oil involving autocatalytic hydrolysis employing microwave irradiation. For this process, however, a surfactant had to be added to the mixture to reach a satisfactory emulsion; furthermore, the reaction achieves equilibrium at $96.6 \%$ of conversion into FFA after four h at 195 degC. Therefore, the use of ultrasound for oil hydrolysis catalyzed by vegetal lipases features a considerable enhancement in intensification of an eco-friendly process.

The reports in the literature employing castor bean seeds as a source of lipase for triglyceride hydrolysis reactions use the seeds in the oil-free form. Coelho et al. (Coelho et al., 2013) used lipase from oil-free castor seeds $(0.075-0.090 \mathrm{~mm})$ to produce FFA by hydrolysis of vegetable oils (corn and sunflower). The maximum percentage of hydrolysis of corn oil $(84.0 \%)$ and sunflower $(76.4 \%)$ was reached in $60 \% \mathrm{w} / \mathrm{w}$ oil, $0.1 \mathrm{M}$ acetate, $\mathrm{pH} 4.5,33 \mathrm{degC}$, and $5 \% \mathrm{~m} / \mathrm{m}$ seed particles after 70 and $80 \mathrm{~min}$ of reaction. Performing the enzymatic hydrolysis of canola oil, Avelar et al., (Avelar et al., 2013), achieved complete hydrolysis of the oil at $37.5 \mathrm{degC}$, buffer/oil ratio $22.1 \%$ after 2 hours, using castor seeds without oil (2.0\% of mass ratio and particles smaller than $1 \mathrm{~mm}$ ). Santos et al. (Santos et al., 2013) evaluate oil-free castor bean seeds $(0.075-$ $0.090 \mathrm{~mm}$ ) and reported the complete hydrolysis of the soybean after 80 minutes at $44.1 \% \mathrm{w} / \mathrm{w}$ oil $/$ buffer (100 mM sodium acetate $\mathrm{pH} 4.5), 37 \mathrm{degC}, 2.0 \% \mathrm{w} / \mathrm{w}$ lipase, and sodium acetate. The results obtained in the present study, $86 \%$ yield after 5 minutes, using in natura seeds, without process costs for seed preparation, show impressive enhancement in the processes that are so far described in the literature.

The oil average extracted in the oil-free catalyst preparation was $47.4+-1.3 \%$, resulting in $21 \%$ of the initial seed mass after sifting. From the optimum conditions, it was taken that for $10 \mathrm{~g}$ of Crambe oil, $6.1 \mathrm{~g}$ of in natura seeds were used, while $1.8 \mathrm{~g}$ of oil-free was necessary, representing $8.6 \mathrm{~g}$ of seed. The higher performance of the in natura seeds can be explained by the presence of components in the lipase that contribute to its activity. Ory (1969) reported the existence of three elements in castor bean lipase, a solid fraction, called apoenzyme, a lipid cofactor, and an activator protein, and concluded that for maximal lipase activity, all the components are necessary. The use of in natura seeds, thus, reflects in more enzymatic activity and can be considered more advantageous for the oil hydrolysis. On the other hand, the use of oil-free seeds can benefit from the residues of the castor oil industry. 


\section{Conclusion}

To improve the yield of the hydrolysis of Crambe oil using seeds of castor beans as the catalyst, the use of ultrasound in the reaction was evaluated using two forms of seeds, in natura and oil-free. The CCRD factorial design was employed to assess each form of the seed particles, and optimum conditions were found, reaching approximately $86 \%$ yield after 5 minutes of ultrasound reaction for in natura seed particles and $73 \%$ for the oil-free seeds. Mathematical modeling, based on a Ping Pong Bi Bi kinetic mechanism, was applied for the experimental kinetic data representation. From unrelated experiments, the FFA concentration values were predicted using the estimated kinetic constants, demonstrating the suitability of the model for process optimization and understanding of the mechanisms in the ultrasound-assisted enzymatic hydrolysis of oils employing vegetal lipases. The potential of the process of ultrasonic enzymatic hydrolysis of oil using castor bean seeds as a source of lipases is highlighted since high conversions were achieved in an impressive short time. The best yield was obtained with the use of in natura seeds, which do not undergo any preparation process resulting in a much lower cost than compared to the use of animal or microbial lipase enzymes that are usually commercialized.

\section{Acknowledgments}

This study was financed in part by the Coordenacao de Aperfeicoamento de Pessoal de Nivel Superior Brasil (CAPES) - Finance Code 001. The authors would like to thank Professor Himanshu Mishra from King Abdullah University of Science and Technology (KAUST), for the possibility of the NMR analysis.

\section{References}

Abigor, R.D., Uadia, P.O., Foglia, T.A., Haas, M.J., Scott, K., Savary, B.J., 2002. Partial purification and properties of lipase from germinating seeds of jatropha curcas L. JAOCS, J. Am. Oil Chem. Soc. 79, $1123-1126$.

Al-Zuhair, S., Hasan, M., Ramachandran, K.B., 2003. Kinetics of the enzymatic hydrolysis of palm oil by lipase. Process Biochem. 38, 1155-1163. https://doi.org/10.1016/S0032-9592(02)00279-0

Almeida, L., Corazza, M.L., Sassaki, G.L., Voll, F.A.P., 2017. Experimental study and kinetic modeling of waste frying soybean oil hydrolysis in subcritical water. React. Kinet. Mech. Catal. https://doi.org/10.1007/s11144-017-1175-1

AOCS, 1996. Official Methods and Recommended Practices of the American Oil Chemists' Society, (Ca 5a-40). Am. Oil Chem. Soc. Champaign, IL. 4th Ed.

Avelar, M.H.M., Cassimiro, D.M.J., Santos, K.C., Domingues, R.C.C., De Castro, H.F., Mendes, A.A., 2013. Hydrolysis of vegetable oils catalyzed by lipase extract powder from dormant castor bean seeds. Ind. Crops Prod. 44, 452-458. https://doi.org/10.1016/j.indcrop.2012.10.011

Awadallak, J.A., Reinehr, T.O., Molinari, D., Raizer, E., Cardozo-Filho, L., da Silva, E.A., da Silva, C., 2016. The effect of ultrasound on the hydrolysis of soybean oil catalyzed by phospholipase. Eur. J. Lipid Sci. Technol. https://doi.org/10.1002/ejlt.201600154

Barnebey, H.L., Brown, A.C., 1948. Continuous fat splitting plants using the colgate-emery process. J. Am. Oil Chem. Soc. 25, 95-99. https://doi.org/10.1007/BF02579733

Barton, S., Bullock, C., Weir, D., 1996. The effects of ultrasound on the activities of some glycosidase enzymes of industrial importance. Enzyme Microb. Technol. https://doi.org/10.1016/0141-0229(95)000925

Bressani, A.P.P., Garcia, K.C.A., Hirata, D.B., Mendes, A.A., 2014. Production of alkyl esters from macaw palm oil by a sequential hydrolysis/esterification process using heterogeneous biocatalysts: Optimization by response surface methodology. Bioprocess Biosyst. Eng. 38, 287-297. https://doi.org/10.1007/s00449-014$1267-5$ 
Campillo-Alvarado, G., Tovar-Miranda, R., 2013. Recent advances and applications of the lipolytic activity of Carica papaya latex. J. Mol. Catal. B Enzym. https://doi.org/10.1016/j.molcatb.2013.01.015

Cavalcanti-Oliveira, E. d'Avila, da Silva, P.R., Ramos, A.P., Aranda, D.A.G., Freire, D.M.G., 2010. Study of Soybean Oil Hydrolysis Catalyzed by Thermomyces lanuginosus Lipase and Its Application to Biodiesel Production via Hydroesterification. Enzyme Res. 2011, 618692. https://doi.org/10.4061/2011/618692

Cavalcanti, E.D.C., Maciel, F.M., Villeneuve, P., Lago, R.C.A., Machado, O.L.T., Freire, D.M.G., 2007. Acetone powder from dormant seeds of Ricinus communis L: Lipase activity and presence of toxic and allergenic compounds, in: Applied Biochemistry and Biotechnology. pp. 57-65. https://doi.org/10.1007/s12010-0079039-1

Chiplunkar, P.P., Zhao, X., Tomke, P.D., Noro, J., Xu, B., Wang, Q., Silva, C., Pratap, A.P., Cavaco-Paulo, A., 2018. Ultrasound-assisted lipase catalyzed hydrolysis of aspirin methyl ester. Ultrason. Sonochem. https://doi.org/10.1016/j.ultsonch.2017.08.004

Coelho, A.D., Santos, K.C., Domingues, R.C.C., Mendes, A.A., 2013. Producao de concentrados de acidos graxos por hidrolise de oleos vegetais mediada por lipase vegetal. Quim. Nova 36, 1164-1169. https://doi.org/10.1590/S0100-40422013000800015

Corradini, F.A.S., Alves, E.S., Kopp, W., Ribeiro, M.P.A., Mendes, A.A., Tardioli, P.W., Giordano, R.C., Giordano, R.L.C., 2019. Kinetic study of soybean oil hydrolysis catalyzed by lipase from solid castor bean seeds. Chem. Eng. Res. Des. https://doi.org/10.1016/j.cherd.2019.02.008

Da Silva, E.C., Mendes, P.R., Brito, Y.C., Meneghetti, M.R., Meneghetti, S.M.P., $2016 . \quad$ Hydrolysis of triacylglyceridesin the presence of tin(IV) catalysts. Catal. Commun. 78, 7-10. https://doi.org/10.1016/j.catcom.2016.01.032

De Freitas, V.O., Matte, C.R., Poppe, J.K., Rodrigues, R.C., Ayub, M.A.Z., 2019. Ultrasoundassisted transesterification of soybean oil using combi-lipase biocatalysts. Brazilian J. Chem. Eng. https://doi.org/10.1590/0104-6632.20190362s20180455

de Sousa, J.S., Cavalcanti-Oliveira, E. d A., Aranda, D.A.G., Freire, D.M.G., 2010. Application of lipase from the physic nut (Jatropha curcas L.) to a new hybrid (enzyme/chemical) hydroesterification process for biodiesel production. J. Mol. Catal. B Enzym. 65, 133-137. https://doi.org/10.1016/j.molcatb.2010.01.003

Devaraj, K., Aathika, S., Mani, Y., Thanarasu, A., Periyasamy, K., Periyaraman, P., Velayutham, K., Subramanian, S., 2018. Experimental investigation on cleaner process of enhanced fat-oil extraction from alkaline leather fleshing waste. J. Clean. Prod. https://doi.org/10.1016/j.jclepro.2017.11.089

dos Santos, L.K., Hatanaka, R.R., de Oliveira, J.E., Flumignan, D.L., 2019. Production of biodiesel from crude palm oil by a sequential hydrolysis/esterification process using subcritical water. Renew. Energy 633-640. https://doi.org/https://doi.org/10.1016/j.renene.2018.06.102

Du, W., Li, W., Sun, T., Chen, X., Liu, D., 2008. Perspectives for biotechnological production of biodiesel and impacts. Appl. Microbiol. Biotechnol. https://doi.org/10.1007/s00253-008-1448-8

Eastmond, P.J., 2004. Cloning and characterization of the acid lipase from Castor beans. J. Biol. Chem. 279, 45540-45545. https://doi.org/10.1074/jbc.M408686200

El-Hefnawy, M.E., Sakran, M., 2014. Characteristics of lipase in dormant seeds catalysed hydrolysis of olive oil in SDS-olive oil reversed microemulsions. Can. J. Chem. Eng. 92, 1335-1339. https://doi.org/10.1002/cjce.21990

Feiten, M.C., Dalla Rosa, C., Treichel, H., Furigo, A., Zenevicz, M.C., de Oliveira, D., Vladimir Oliveira, J., 2014. Batch and fed-batch enzymatic hydrolysis of soybean oil under ultrasound irradiation. Biocatal. Agric. Biotechnol. 3, 83-85. https://doi.org/10.1016/j.bcab.2013.12.003 
Ferreira-Dias, S., da Fonseca, M.M.R., 1995. The effect of substrate hydrophobicity on the kinetic behaviour of immobilized Candida rugosa lipase. Biocatal. Biotransformation 13, 99-110. https://doi.org/10.3109/10242429509015216

Froment, M.T., Lockridge, O., Masson, P., 1998. Resistance of butyrylcholinesterase to inactivation by ultrasound: Effects of ultrasound on catalytic activity and subunit association. Biochim. Biophys. Acta Protein Struct. Mol. Enzymol. 1387, 53-64. https://doi.org/10.1016/S0167-4838(98)00105-8

Fuchs, C., Vine, N., Hills, M.J., 1996. Purification and characterization of the acid lipase from the endosperm of castor oil seeds. J. Plant Physiol. 149, 23-29. https://doi.org/10.1016/S0176-1617(96)80168-4

Goni, M.L., Pacheco, C., Constenla, D.T., Carelli, A.A., 2018. Solvent-free enzymatic hydrolysis of non-polar lipids in crude sunflower lecithin using phospholipase A1 (Lecitase(r) Ultra). Biocatal. Biotransformation. https://doi.org/10.1080/10242422.2017.1376662

Han, B., Jiang, J., Zhang, W., Yin, F., Liu, S., Zhao, X., Liu, J., Wang, C., Yang, H., 2019. Hydrolysis of rapeseed oil to fatty acids using pyrrolidonium ionic liquids as catalysts. Energy Sources, Part A Recover. Util. Environ. Eff. https://doi.org/10.1080/15567036.2019.1568627

Hills, M.J., Murphy, D.J., 1988. Characterization of lipases from the lipid bodies and microsomal membranes of erucic acid-free oilseed-rape (Brassica napus) cotyledons. Biochem. J. 249, 687-693.

Ho, W.W.S., Ng, H.K., Gan, S., 2016. Advances in ultrasound-assisted transesterification for biodiesel production. Appl. Therm. Eng. https://doi.org/10.1016/j.applthermaleng.2016.02.058

Ilham, Z., Saka, S., 2010. Two-step supercritical dimethyl carbonate method for biodiesel production from Jatropha curcas oil. Bioresour. Technol. https://doi.org/10.1016/j.biortech.2009.10.053

Lazzeri, L., Leoni, O., Conte, L.S., Palmieri, S., 1994. Some technological characteristics and potential uses of Crambe abyssinica products. Ind. Crops Prod. 3, 103-112. https://doi.org/10.1016/0926-6690(94)90083-3

Leong, T.S.H., Wooster, T.J., Kentish, S.E., Ashokkumar, M., 2009. Minimising oil droplet size using ultrasonic emulsification. Ultrason. Sonochem. 16, 721-727. https://doi.org/10.1016/j.ultsonch.2009.02.008

Lerin, L.A., Loss, R.A., Remonatto, D., Zenevicz, M.C., Balen, M., Netto, V.O., Ninow, J.L., Trentin, C.M., Oliveira, J.V., de Oliveira, D., 2014. A review on lipase-catalyzed reactions in ultrasound-assisted systems. Bioprocess Biosyst. Eng. 2381-2394. https://doi.org/10.1007/s00449-014-1222-5

Martinez, A., Mijangos, G.E., Romero-Ibarra, I.C., Hernandez-Altamirano, R., Mena-Cervantes, V.Y., Gutierrez, S., 2018. A novel green one-pot synthesis of biodiesel from Ricinus communis seeds by basic heterogeneous catalysis. J. Clean. Prod. https://doi.org/10.1016/j.jclepro.2018.05.241

Meneguelli de Souza, L.C., Carvalho, L.P. d., Araujo, J.S., Melo, E.J.T. d., Machado, O.L.T., 2018. Cell toxicity by ricin and elucidation of mechanism of Ricin inactivation. Int. J. Biol. Macromol. https://doi.org/10.1016/j.ijbiomac.2018.03.024

Muto, S., Beevers, H., 1974. Lipase Activities in Castor Bean Endosperm during Germination. Plant Physiol. 54, 23-28. https://doi.org/10.1104/pp.54.1.23

Nelder, J.A., Mead, R., 1964. A simplex method for function minimization. Comput. J. 7, 308-313. https://doi.org/10.1093/comjnl/7.4.308

Nguyen, H.C., Lee, H.Y., Su, C.H., Shih, W.J., Chien, C.C., 2020. Green process for fatty acid production from soybean oil through microwave-mediated autocatalytic synthesis. Chem. Eng. Process. - Process Intensif. https://doi.org/10.1016/j.cep.2019.107782

Noor, I.M., Hasan, M., Ramachandran, K.B., 2003. Effect of operating variables on the hydrolysis rate of palm oil by lipase. Process Biochem. 39, 13-20. https://doi.org/10.1016/S0032-9592(02)00263-7 
Ong, L.K., Tran Nguyen, P.L., Soetaredjo, F.E., Ismadji, S., Ju, Y.-H., 2016. Direct reuse of Cu-laden wastewater for non-edible oil hydrolysis: Basic mechanism of metal extraction and fatty acid production. RSC Adv. 6. https://doi.org/10.1039/c5ra23153a

Ozbek, B., Ulgen, K.O., 2000. The stability of enzymes after sonication. Process Biochem. 35, 1037-1043. https://doi.org/10.1016/S0032-9592(00)00141-2

Polachini, T.C., Mulet, A., Telis-Romero, J., Carcel, J.A., 2019. Influence of high-intensity ultrasound application on the kinetics of sugar release from acid suspensions of artichoke (Cynara scolymus) biomass. Chem. Eng. Process. - Process Intensif. https://doi.org/10.1016/j.cep.2019.107681

Posorske, L.H., 1984. Industrial-scale application of enzymes to the fats and oil industry. J. Am. Oil Chem. Soc. 61, 1758-1760. https://doi.org/10.1007/BF02582143

Pourzolfaghar, H., Abnisa, F., Daud, W.M.A.W., Aroua, M.K., 2016. A review of the enzymatic hydroesterification process for biodiesel production. Renew. Sustain. Energy Rev. https://doi.org/10.1016/j.rser.2016.03.048

Romero, M.D., Calvo, L., Alba, C., Daneshfar, A., 2007. A kinetic study of isoamyl acetate synthesis by immobilized lipase-catalyzed acetylation in n-hexane. J. Biotechnol. 127, 269-277. https://doi.org/10.1016/j.jbiotec.2006.07.009

Rooney, D., Weatherley, L.R., 2001. The effect of reaction conditions upon lipase catalysed hydrolysis of high oleate sunflower oil in a stirred liquid-liquid reactor. Process Biochem. 36, 947-953. https://doi.org/10.1016/S0032-9592(01)00130-3

Rosenbrock, H.H., 1963. Some general implicit processes for the numerical solution of differential equations. Comput. J. 5, 329-330.

Salaberria, F., Palla, C., Carrin, M.E., 2017. Hydrolytic Activity of Castor Bean Powder: Effect of Gum Arabic, Lipase and Oil Concentrations. JAOCS, J. Am. Oil Chem. Soc. 94, 741-745. https://doi.org/10.1007/s11746-017-2976-0

Santos, K.C., Cassimiro, D.M.J., Avelar, M.H.M., Hirata, D.B., de Castro, H.F., Fernandez-Lafuente, R., Mendes, A.A., 2013. Characterization of the catalytic properties of lipases from plant seeds for the production of concentrated fatty acids from different vegetable oils. Ind. Crops Prod. 49, 462-470. https://doi.org/10.1016/j.indcrop.2013.05.035

Talukder, M.M.R., Zaman, M.M., Hayashi, Y., Wu, J.C., Kawanishi, T., 2006. Ultrasonication enhanced hydrolytic activity of lipase in water/isooctane two-phase systems. Biocatal. Biotransformation 24, 189-194. https://doi.org/10.1080/10242420500132326

Tavares, F., Petry, J., Sackser, P.R., Borba, C.E., Silva, E.A., 2018a. Use of castor bean seeds as lipase source for hydrolysis of crambe oil. Ind. Crops Prod. 124, 254-264. https://doi.org/10.1016/j.indcrop.2018.06.073

TAVARES, F., SACKSER, P., PINZAN, F., BORBA, C.E., SILVA, E.A., 2015. HIDROLISE DO OLEO DE CRAMBE EMPREGANDO LIPASE VEGETAL EXTRAIDA DE SEMENTES DE DIFERENTES OLEAGINOSAS. https://doi.org/10.5151/chemeng-cobeqic2015-112-32299-245530

Tavares, F., Silva, E.A. Da, Pinzan, F., Canevesi, R.S., Milinsk, M.C., Scheufele, F.B., Borba, C.E., 2018b. Hydrolysis of crambe oil by enzymatic catalysis: An evaluation of the operational conditions. Biocatal. Biotransformation 1-14. https://doi.org/10.1080/10242422.2018.1430786

Tully, R.E., Beevers, H., 1976. Protein bodies of castor bean endosperm: isolation, fractionation, and the characterization of protein components. Plant Physiol. 58, 710-6. https://doi.org/10.1104/pp.58.6.710

Vercet, A., Burgos, J., Crelier, S., Lopez-Buesa, P., 2001. Inactivation of proteases and lipases by ultrasound. Innov. Food Sci. Emerg. Technol. 2, 139-150. https://doi.org/10.1016/S1466-8564(00)00037-0 
Villeneuve, P., 2003. Plant lipases and their applications in oils and fats modification. Eur. J. Lipid Sci. Technol. https://doi.org/10.1002/ejlt.200390061

Wang, J., Wang, S., Li, Z., Gu, S., Wu, X., Wu, F., 2015. Ultrasound irradiation accelerates the lipase-catalyzed synthesis of methyl caffeate in an ionic liquid. J. Mol. Catal. B Enzym. 111, 21-28. https://doi.org/10.1016/j.molcatb.2014.11.006

Wazilewski, W.T., Bariccatti, R.A., Martins, G.I., Secco, D., Souza, S.N.M. de, Rosa, H.A., Chaves, L.I., 2013. Study of the methyl crambe (Crambe abyssinica Hochst) and soybean biodiesel oxidative stability. Ind. Crops Prod. 43, 207-212. https://doi.org/10.1016/j.indcrop.2012.07.046

Xiao, H., Li, Y., Wang, H., 2017. A stochastic kinetic study of preparing fatty acid from rapeseed oil via subcritical hydrolysis. Appl. Energy. https://doi.org/10.1016/j.apenergy.2017.05.013

Tables:

Table 1. CCRD factorial design experiment and yield results for reactions performed with ultrasound using seeds in natura (buffer solution, $\mathrm{pH} 4.2,3$ minutes).

\begin{tabular}{llllllll}
\hline & & Coded design levels & Coded design levels & Real values & Real values & & \\
\hline Exp & Po (\%) & B/O & C/S & Po (\%) & B/O & C/S & Yield (\%) \\
1 & -1 & -1 & -1 & 45.00 & 0.45 & 0.07 & 20.71 \\
2 & 1 & -1 & -1 & 85.00 & 0.45 & 0.07 & 11.13 \\
3 & -1 & 1 & -1 & 45.00 & 1.55 & 0.07 & 40.92 \\
4 & 1 & 1 & -1 & 85.00 & 1.55 & 0.07 & 39.00 \\
5 & -1 & -1 & 1 & 45.00 & 0.45 & 0.25 & 49.73 \\
6 & 1 & -1 & 1 & 85.00 & 0.45 & 0.25 & 51.76 \\
7 & -1 & 1 & 1 & 45.00 & 1.55 & 0.25 & 84.51 \\
8 & 1 & 1 & 1 & 85.00 & 1.55 & 0.25 & 83.48 \\
9 & -1.68 & 0 & 0 & 31.40 & 1.00 & 0.16 & 59.54 \\
10 & 1.68 & 0 & 0 & 98.64 & 1.00 & 0.16 & 56.08 \\
11 & 0 & -1.68 & 0 & 65.00 & 0.07 & 0.16 & 9.39 \\
12 & 0 & 1.68 & 0 & 65.00 & 1.93 & 0.16 & 72.20 \\
13 & 0 & 0 & -1.68 & 65.00 & 1.00 & 0.01 & 3.97 \\
14 & 0 & 0 & 1.68 & 65.00 & 1.00 & 0.31 & 78.28 \\
PC1 & 0 & 0 & 0 & 65.00 & 1.00 & 0.16 & 58.92 \\
PC2 & 0 & 0 & 0 & 65.00 & 1.00 & 0.16 & 61.51 \\
PC3 & 0 & 0 & 0 & 65.00 & 1.00 & 0.16 & 56.75 \\
\hline
\end{tabular}

Table 2. Estimated parameter values of the kinetic model of Crambe oil enzymatic hydrolysis using in natura seeds.

\begin{tabular}{ll}
\hline Parameter & Value \\
\hline$k_{1}\left(\mathrm{~kg} \mathrm{~mol}^{-1} \mathrm{~h}^{-1}\right)$ & $1.51 \times 10^{5}$ \\
$k_{2}\left(\mathrm{~h}^{-1}\right)$ & $1.27 \times 10^{5}$ \\
$k_{3}\left(\mathrm{~kg} \mathrm{~mol}^{-1} \mathrm{~h}^{-1}\right)$ & $4.71 \times 10^{5}$ \\
$k_{4}\left(\mathrm{~kg}^{2} \mathrm{~mol}^{-2} \mathrm{~h}^{-1}\right)$ & $2.28 \times 10^{6}$ \\
$k_{5}\left(\mathrm{~kg} \mathrm{~mol}^{-1} \mathrm{~h}^{-1}\right)$ & $3.24 \times 10^{6}$ \\
$k_{6}\left(\mathrm{~h}^{-1}\right)$ & $3.26 \times 10^{4}$ \\
$k\left(\mathrm{~kg} \mathrm{~mol}^{-1} \mathrm{~h}^{-1}\right)$ & $1.10 \times 10^{2}$ \\
$k\left(\mathrm{~kg}^{2} \mathrm{~mol}^{-2} \mathrm{~h}^{-1}\right)$ & $2.59 \times 10^{6}$ \\
$k_{9}\left(\mathrm{~kg} \mathrm{~mol}^{-1} \mathrm{~h}^{-1}\right)$ & $2.50 \times 10^{5}$
\end{tabular}




\begin{tabular}{ll}
\hline Parameter & Value \\
\hline$k_{10}\left(\mathrm{~h}^{-1}\right)$ & $8.59 \times 10^{4}$ \\
$k_{11}\left(\mathrm{~kg} \mathrm{~mol}^{-1} \mathrm{~h}^{-1}\right)$ & $2.11 \times 10^{5}$ \\
$k_{12}\left(\mathrm{~kg}^{2} \mathrm{~mol}^{-2} \mathrm{~h}^{-1}\right)$ & $1.14 \times 10^{6}$ \\
\hline
\end{tabular}

Table 3. Validation of the kinetic model of Crambe oil enzymatic hydrolysis using in natura seeds.

\begin{tabular}{|c|c|c|c|c|c|c|}
\hline Exp. & Po $(\%)$ & $\mathrm{B} / \mathrm{O}$ & $\mathrm{C} / \mathrm{S}$ & $\begin{array}{l}\text { Experimental } \\
\text { Yield (FFA) } \\
(\%)\end{array}$ & $\begin{array}{l}\text { Simulated } \\
\text { Yield (FFA) } \\
(\%)\end{array}$ & $\begin{array}{l}\text { Deviation }^{\mathrm{a}} \\
(\%)\end{array}$ \\
\hline 12 & 65 & 1.92 & 0.16 & 74.70 & 69.12 & 7.48 \\
\hline 14 & 65 & 1 & 0.31 & 80.23 & 84.54 & 5.38 \\
\hline 15 & 65 & 1 & 0.16 & 62.62 & 78.11 & 24.73 \\
\hline 16 & 65 & 1 & 0.16 & 64.98 & 78.11 & 20.21 \\
\hline 17 & 65 & 1 & 0.16 & 60.64 & 78.11 & 28.81 \\
\hline
\end{tabular}

a Deviation: $D=100 \frac{\text { Absolute }(E-S)}{E}$, where $E$ is the Experimental, $S$ is the Simulated Yield.

Table 4. CCRD factorial design experiment and yield results for reactions performed with ultrasound using oil-free seeds (buffer solution, $\mathrm{pH} 4.2,3$ minutes).

\begin{tabular}{|c|c|c|c|c|c|c|c|}
\hline & Coded design levels & Coded design levels & Coded design levels & Real values & Real values & Real values & Real va \\
\hline Exp. & Po (\%) & $\mathrm{B} / \mathrm{O}$ & $\mathrm{C} / \mathrm{S}$ & Po (\%) & $\mathrm{B} / \mathrm{O}$ & $\mathrm{C} / \mathrm{S}$ & Yield \\
\hline 1 & -1 & -1 & -1 & 45.00 & 1.40 & 0.02 & 0.02 \\
\hline 2 & 1 & -1 & -1 & 85.00 & 1.40 & 0.02 & 0.02 \\
\hline 3 & -1 & 1 & -1 & 45.00 & 2.20 & 0.02 & 0.02 \\
\hline 4 & 1 & 1 & -1 & 85.00 & 2.20 & 0.02 & 0.02 \\
\hline 5 & -1 & -1 & 1 & 45.00 & 1.40 & 0.05 & 0.05 \\
\hline 6 & 1 & -1 & 1 & 85.00 & 1.40 & 0.05 & 0.05 \\
\hline 7 & -1 & 1 & 1 & 45.00 & 2.20 & 0.05 & 0.05 \\
\hline 8 & 1 & 1 & 1 & 85.00 & 2.20 & 0.05 & 0.05 \\
\hline 9 & -1.68 & 0 & 0 & 31.40 & 1.80 & 0.035 & 0.035 \\
\hline 10 & 1.68 & 0 & 0 & 98.64 & 1.80 & 0.035 & 0.035 \\
\hline 11 & 0 & -1.68 & 0 & 65.00 & 1.13 & 0.035 & 0.035 \\
\hline 12 & 0 & 1.68 & 0 & 65.00 & 2.47 & 0.035 & 0.035 \\
\hline 13 & 0 & 0 & -1.68 & 65.00 & 1.80 & 0.01 & 0.01 \\
\hline 14 & 0 & 0 & 1.68 & 65.00 & 1.80 & 0.06 & 0.06 \\
\hline $\mathrm{PC} 1$ & 0 & 0 & 0 & 65.00 & 1.80 & 0.035 & 0.035 \\
\hline $\mathrm{PC} 2$ & 0 & 0 & 0 & 65.00 & 1.80 & 0.035 & 0.035 \\
\hline PC3 & 0 & 0 & 0 & 65.00 & 1.80 & 0.035 & 0.035 \\
\hline
\end{tabular}

Table 5. Estimated parameter values for the kinetic model of the Crambe oil enzymatic hydrolysis using oil-free seeds.

\begin{tabular}{ll}
\hline Parameter & Value \\
\hline$k_{1}\left(\mathrm{~kg} \mathrm{~mol}^{-1} \mathrm{~h}^{-1}\right)$ & $7.22 \times 10^{4}$ \\
$k_{2}\left(\mathrm{~h}^{-1}\right)$ & $2.24 \times 10^{2}$
\end{tabular}




\begin{tabular}{ll}
\hline Parameter & Value \\
\hline$k_{3}\left(\mathrm{~kg} \mathrm{~mol}^{-1} \mathrm{~h}^{-1}\right)$ & $1.68 \times 10^{6}$ \\
$k_{4}\left(\mathrm{~kg}^{2} \mathrm{~mol}^{-2} \mathrm{~h}^{-1}\right)$ & $5.18 \times 10^{9}$ \\
$k_{5}\left(\mathrm{~kg} \mathrm{~mol}^{-1} \mathrm{~h}^{-1}\right)$ & $9.02 \times 10^{4}$ \\
$k_{6}\left(\mathrm{~h}^{-1}\right)$ & $2.80 \times 10^{5}$ \\
$k_{7}\left(\mathrm{~kg} \mathrm{~mol}^{-1} \mathrm{~h}^{-1}\right)$ & $1.00 \times 10^{6}$ \\
$k_{8}\left(\mathrm{~kg}^{2} \mathrm{~mol}^{-2} \mathrm{~h}^{-1}\right)$ & $2.32 \times 10^{7}$ \\
$k_{9}\left(\mathrm{~kg} \mathrm{~mol}^{-1} \mathrm{~h}^{-1}\right)$ & $6.95 \times 10^{4}$ \\
$k_{10}\left(\mathrm{~h}^{-1}\right)$ & $8.02 \times 10^{4}$ \\
$k_{11}\left(\mathrm{~kg} \mathrm{~mol}^{-1} \mathrm{~h}^{-1}\right)$ & $1.03 \times 10^{6}$ \\
$k_{12}\left(\mathrm{~kg}^{2} \mathrm{~mol}^{-2} \mathrm{~h}^{-1}\right)$ & $7.67 \times 10^{6}$ \\
\hline
\end{tabular}

Table 6. Validation of the kinetic model of the Crambe oil enzymatic hydrolysis using oil-free seeds.

\begin{tabular}{lllllll}
\hline Exp. & Po $(\%)$ & B/O & C/S & $\begin{array}{l}\text { Experimental } \\
\text { Yield (FFA) }\end{array}$ & $\begin{array}{l}\text { Simulated } \\
\text { Yield (FFA) }\end{array}$ & $\begin{array}{l}\text { Deviation }^{\text {a }} \\
(\%)\end{array}$ \\
\hline 12 & 65 & 2.47 & 0.04 & 67.35 & 55.34 & 17.83 \\
14 & 65 & 1.8 & 0.06 & 72.07 & 64.58 & 10.39 \\
15 & 65 & 1.8 & 0.04 & 65.27 & 59.02 & 9.57 \\
16 & 65 & 1.8 & 0.04 & 65.39 & 59.02 & 9.74 \\
17 & 65 & 1.8 & 0.04 & 65.40 & 59.02 & 9.75 \\
\hline
\end{tabular}

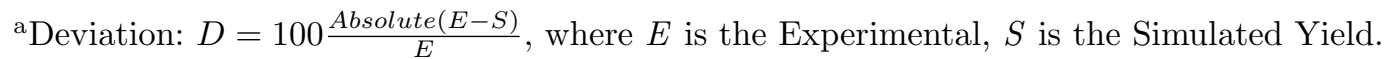

Table 7. Comparison of the enzymatic seed particles.

\begin{tabular}{llll}
\hline Variable & Variable & In natura & Oil-free \\
\hline Shaker [55] & Temperature & $33^{\circ} \mathrm{C}$ & $43,8^{\circ} \mathrm{C}$ \\
& Mass ratio B/O & 0,87 & 1,8 \\
& Mass ratio C/S & 0,31 & 0,07 \\
& Maximum yield after 4 hours. & $91 \%$ & $88 \%$ \\
Ultrasound & Ultrasound power & $69.9 \%$ & $67.8 \%$ \\
& Mass ratio B/O & 1.79 & 1.67 \\
& Mass ratio C/S & 0.25 & 0.06 \\
& Maximum yield after 5 minutes. & $86.5 \%$ & $73.0 \%$ \\
& Maximum yield after 5 minutes in ultrasound followed by 30 minutes in a shaker. & $90.0 \%$ & $76.6 \%$ \\
\hline
\end{tabular}

\section{Figure Captions:}

Figure 1. Standardized effect estimative of the process variables on the hydrolysis yield of Crambe oil using in natura castor seeds.

Figure 2. Response surface for the effects of a) ultrasound power versus buffer solution/oil mass ratio, b) ultrasound power versus catalyst/substrate mass ratio, and c) catalyst/substrate mass ratio versus buffer solution/oil mass ratio on the yield of enzymatic hydrolysis of Crambe oil using in natura seeds.

Figure 3. Crambe oil enzymatic hydrolysis kinetics with in natura seeds. a) $\mathrm{C}_{\mathrm{FFA}}\left(\mathrm{mol} \mathrm{kg}^{-1}\right)$, b) $\mathrm{C}_{\mathrm{MAG}}$ $\left(\mathrm{mol} \mathrm{kg}{ }^{-1}\right)$, c) $\mathrm{C}_{\mathrm{DAG}}\left(\mathrm{mol} \mathrm{kg}^{-1}\right)$, d) $\mathrm{C}_{\mathrm{TAG}}\left(\mathrm{mol} \mathrm{kg}^{-1}\right)$, e) $\mathrm{C}_{\mathrm{GL}}(\mathrm{mol} \mathrm{kg}-1)$, and f) $\mathrm{C}_{\mathrm{w}}\left(\mathrm{mol} \mathrm{kg}^{-1}\right)$. Conditions: ultrasound power $70 \%$, buffer solution/oil ratio of 1.8 , catalyst/substrate ratio of $0.25, \mathrm{pH} 4.2$. 
Figure 4. Standardized effect estimative of the process variables on the hydrolysis yield of Crambe oil using oil-free castor seeds.

Figure 5. Response surface for the effects of a) ultrasound power versus buffer solution/oil mass ratio, b) ultrasound power versus catalyst/substrate mass ratio, and c) catalyst/substrate mass ratio versus buffer solution/oil mass ratio on the yield of enzymatic hydrolysis of Crambe oil using oil-free seeds.

Figure 6. Crambe oil enzymatic hydrolysis kinetics with oil-free seeds. a) $\mathrm{C}_{\mathrm{FFA}}\left(\mathrm{mol} \mathrm{kg}^{-1}\right)$, b) $\mathrm{C}_{\mathrm{MAG}}$ $\left(\operatorname{mol~kg}{ }^{-1}\right)$, c) $\mathrm{C}_{\mathrm{DAG}}\left(\mathrm{mol} \mathrm{kg}{ }^{-1}\right)$, d) $\mathrm{C}_{\mathrm{TAG}}\left(\mathrm{mol} \mathrm{kg}^{-1}\right)$, e) $\mathrm{C}_{\mathrm{GL}}\left(\mathrm{mol} \mathrm{kg}^{-1}\right)$, and f) $\mathrm{C}_{\mathrm{w}}\left(\mathrm{mol} \mathrm{kg}^{-1}\right)$. Conditions: ultrasound power $68 \%$, buffer solution/oil ratio of 1.7 , catalyst/substrate ratio of $0.06, \mathrm{pH} 4.2$.

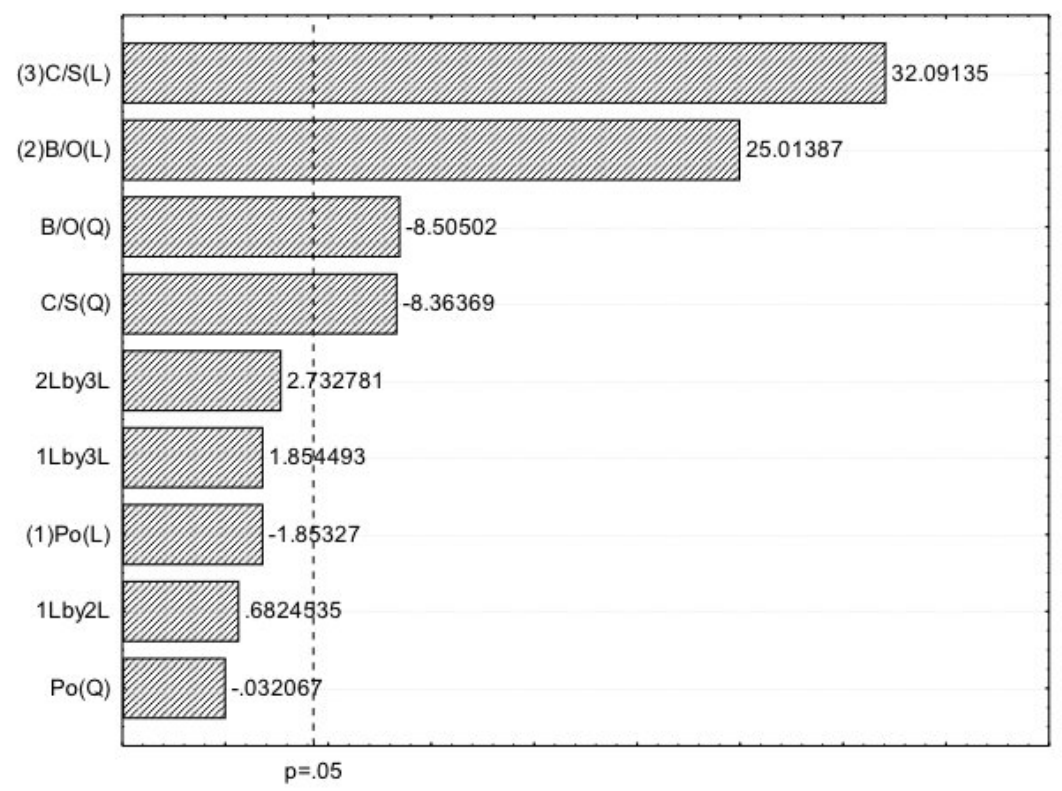


a)

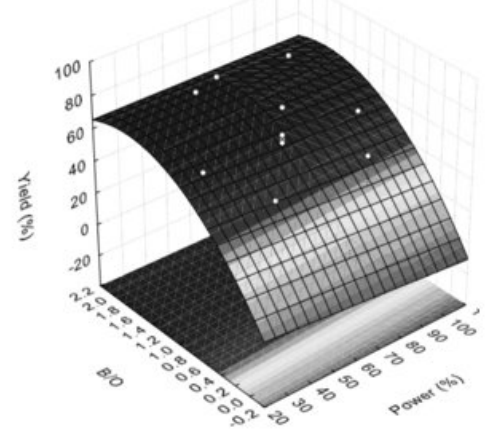

b)

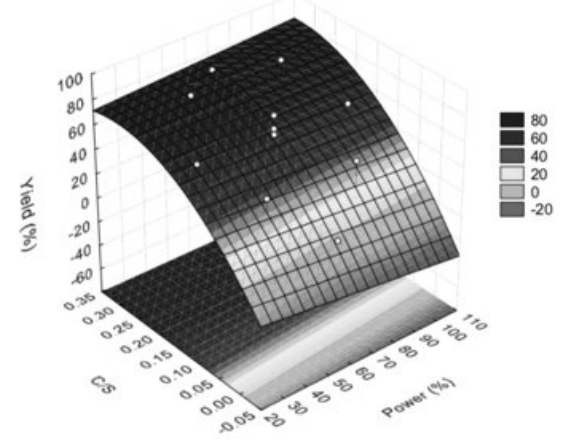

c)

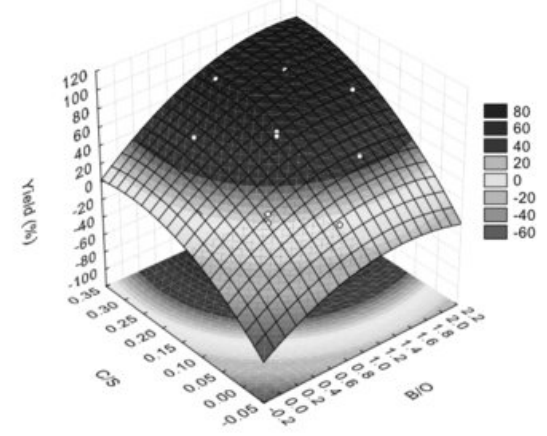



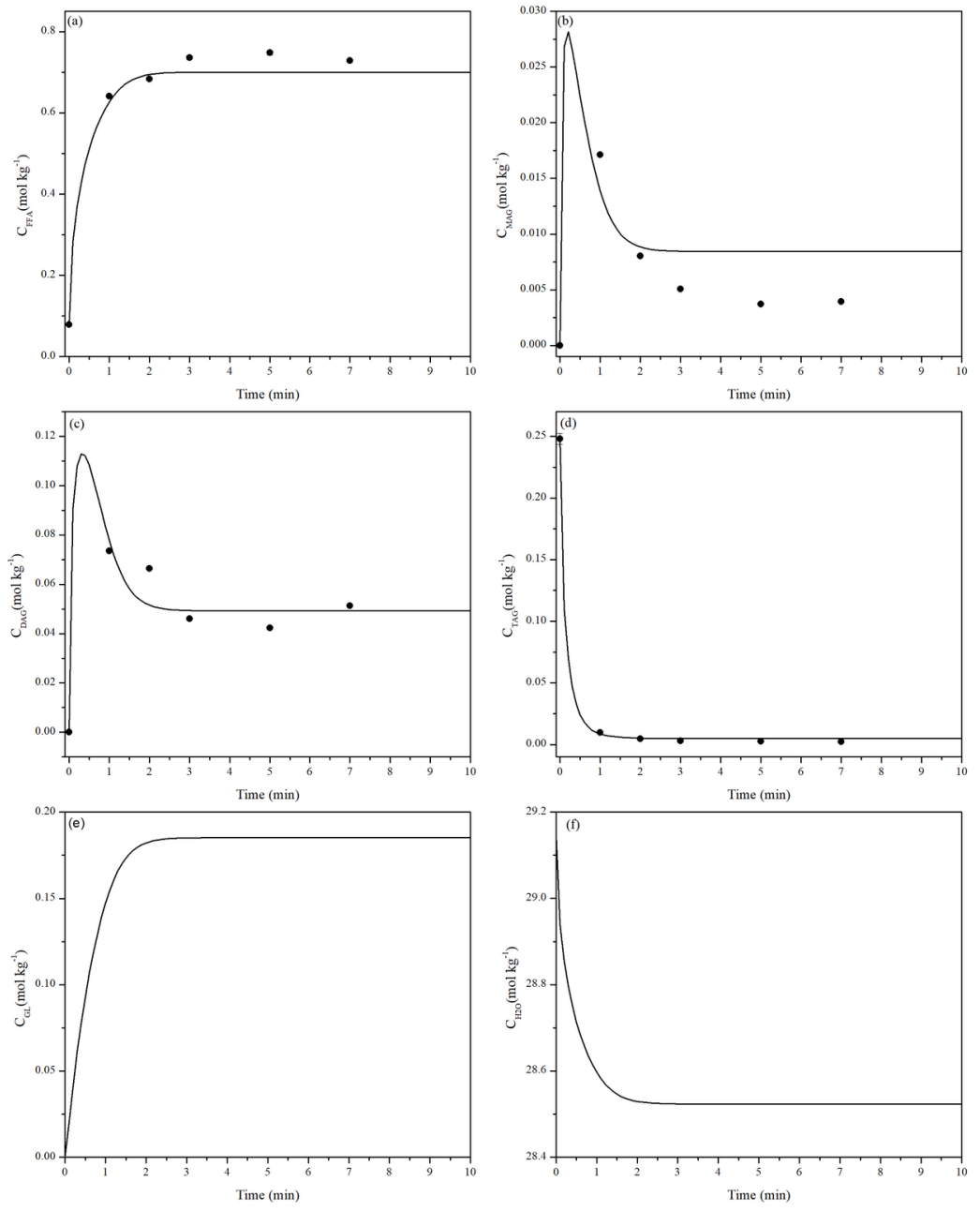

19 


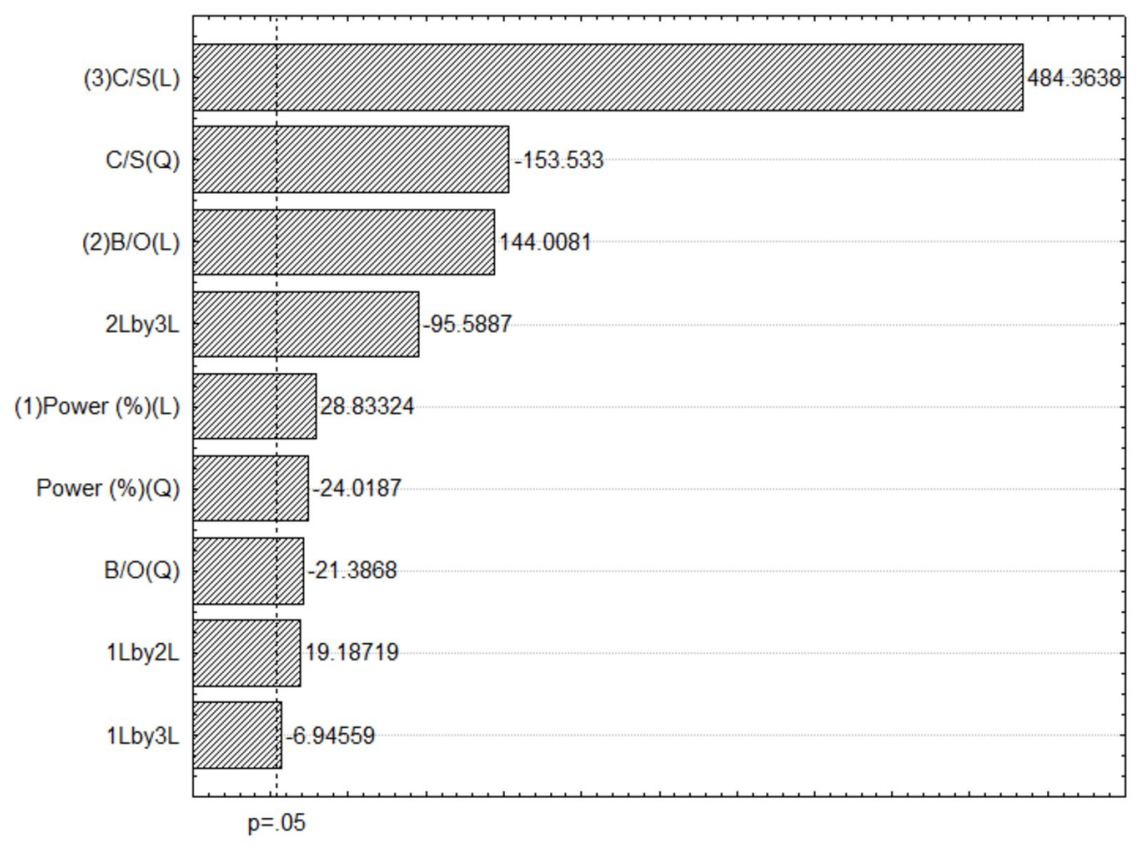

a)

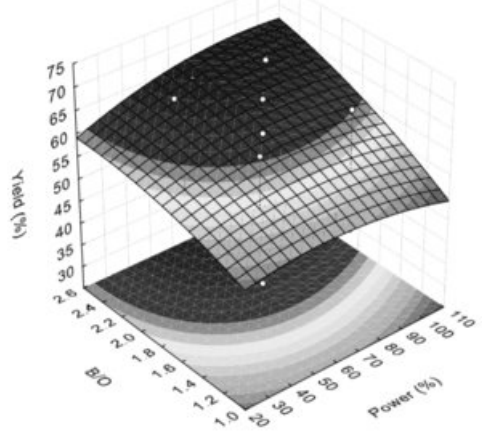

b)

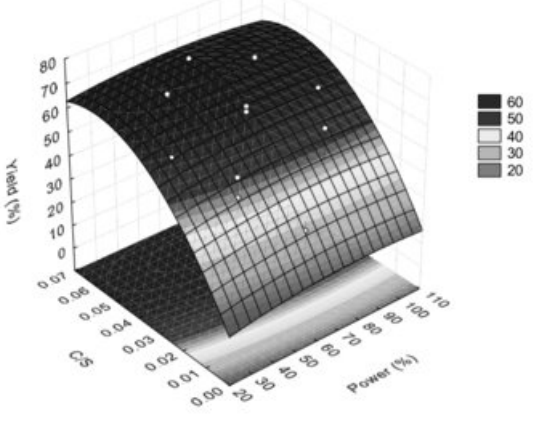

c)

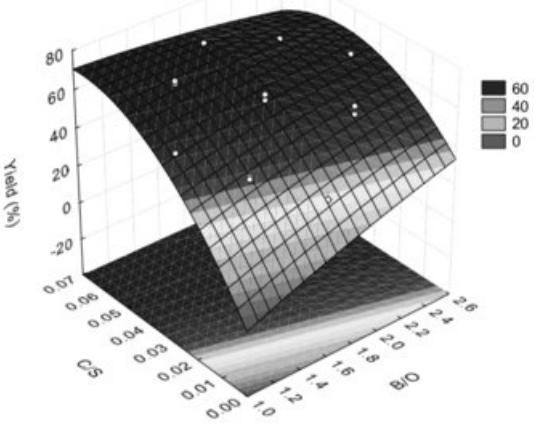



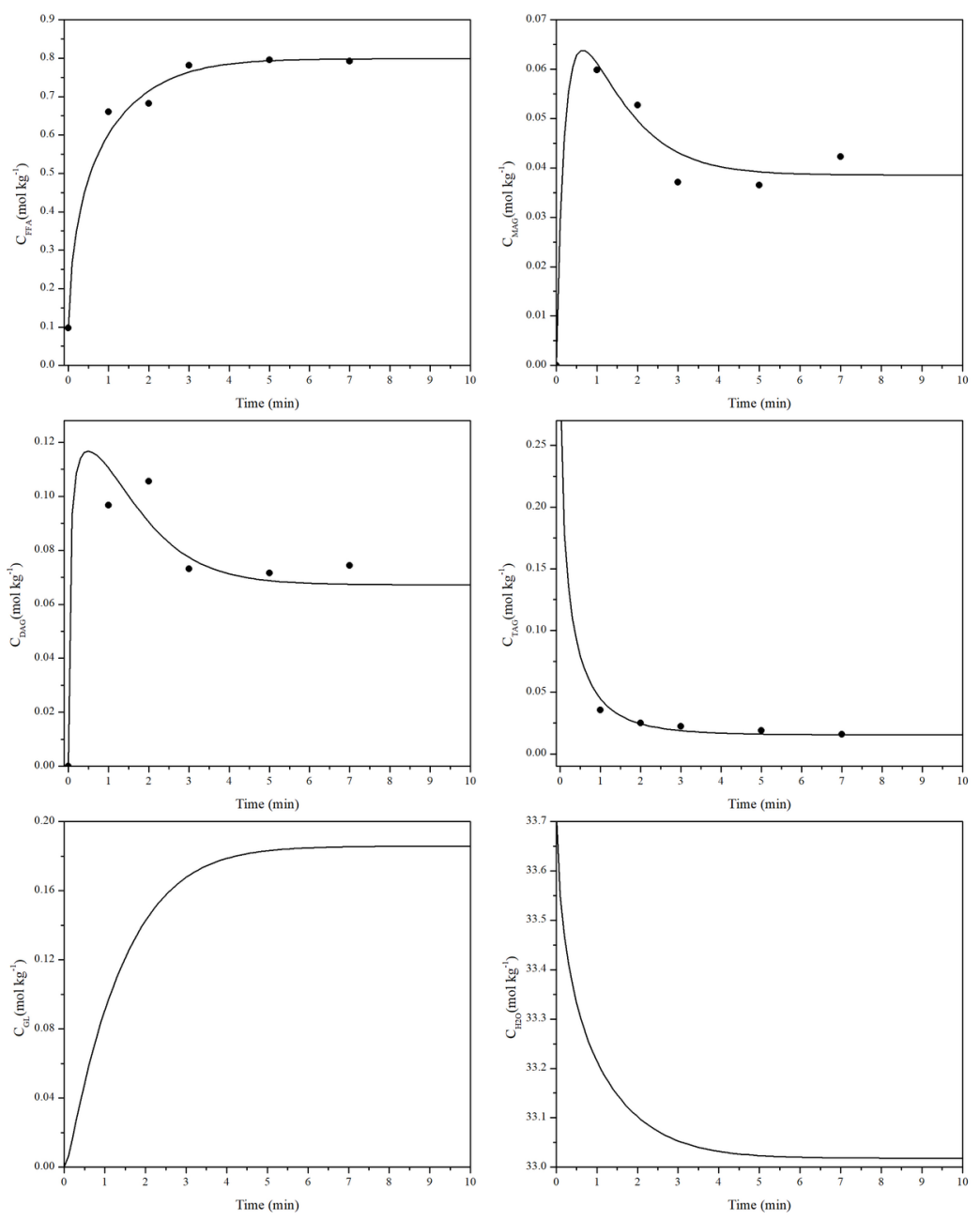